\title{
The mediating roles of functional limitations and social support on the relationship between vision impairment and depressive symptoms in older adults
}

\author{
Xiuquan Gong ${ }^{1}$, Zhao $\mathrm{Ni}^{2}$ and $\mathrm{Bei} \mathrm{Wu}^{3,4 *}$ \\ ${ }^{1}$ Social Science and Public Administration, East China University of Science and Technology, Shanghai, \\ China, ${ }^{2}$ School of Nursing, Duke University, North Carolina, USA, ${ }^{3}$ Rory Meyers College of Nursing, \\ New York University, ${ }^{4}$ NYC Aging Incubator, New York University, New York, USA \\ ${ }^{\star}$ Corresponding author. Email: bei.wu@nyu.edu
}

(Accepted 13 July 2018; first published online 5 September 2018)

\begin{abstract}
Vision impairment is prevalent and it is strongly associated with depressive symptoms in older adults. This study aimed to investigate the mediating roles of functional limitations and social support on the relationship between vision impairment and depressive symptoms in older adults. This study used data from a probability-based sample of 1,093 adults aged 60 and older in Shanghai, China. Structural equation models were used to examine the structural relationships among sets of variables simultaneously, including vision impairment, activities of daily living ADLs, instrumental ADLs (IADLs), friends support, family support, relatives support and depressive symptoms. The bootstrapping method and the program PRODCLIN were used to test the indirect effects of these variables. This study found that vision impairment was directly associated with a higher level of depressive symptoms, and the association was partially mediated by functional limitations (IADLs) and social support (friends support). The study demonstrates that improving social support from friends and enhancing social participation for visually impaired older adults can reduce depressive symptoms. More importantly, this study contributes to the knowledge of mediating mechanisms between vision impairment and depressive symptoms.
\end{abstract}

Keywords: vision impairment; depressive symptoms; friends support; instrumental activities of daily living (IADLs); older adults

\section{Introduction}

Vision impairment affects one-fifth of adults over the age of 60 in the world (Brown and Barrett, 2011). The number of visually impaired adults aged 50 and older is 186 million, which represents 13.89 per cent of the global population (World Health Organization, 2012). Previous research suggests a strong link between vision 
impairment and depressive symptoms: older adults with vision impairment are more likely to have depressive symptoms (Heine and Browning, 2004; Augustin et al., 2007; Evans et al., 2007; Hayman et al., 2007; Jin and Wong, 2008; Bernabei et al., 2011; Rees et al., 2013). For example, older adults with vision impairment were 1.43-1.65 times more likely to have suicidal ideation compared to those with normal vision (Kim et al., 2015).

In the literature, functional limitations and social support are often identified as important factors associated with depressive symptoms among visually impaired older adults (Beekman et al., 1995; Rovner et al., 1996; Lebowitz et al., 1997; Penninx et al., 1998; Hybels et al., 2001; Rovner and Casten, 2002; Guerette and Smedema, 2011; Rees et al., 2013). For example, visually impaired older adults often have serious functional limitations associated with depressive symptoms (Branch et al., 1989; Keller et al., 1999; Brody et al., 2001; Burmedi et al., 2002; West et al., 2002; Jang et al., 2003; Schilling et al., 2011; Hochberg et al., 2012). Furthermore, studies have shown that greater support from family and friends is significantly associated with better adaptation to vision impairment and fewer depressive symptoms (Reinhardt, 1996; Mcllvane and Reinhardt, 2001; Horowitz et al., 2003; Reinhardt et al., 2009).

The research reviewed above emphasised the importance of investigating the prevalence and predictors of depressive symptoms in older adults with vision impairment. However, these studies failed to address possible explanatory variables associated with the relationship between vision impairment and depressive symptoms among older adults. Furthermore, family support and friends support were often treated as exogenous independent variables, when in fact they could be endogenous variables. For example, older adults with vision impairment were less likely to participate in social activities than their peers with normal vision, had decreased contact with friends and experienced decreased size of their friendship network (Wang et al., 2008a). Also, in England and Finland, women with greater functional limitations had higher odds of receiving spousal and filial help (Blomgren et al., 2012).

Therefore, it is important to understand the mediation mechanisms between vision impairment and depressive symptoms. A few studies have examined the mediation effects of functional limitations and social support on the relationship between vision impairment and depressive symptoms. However, the results from these studies were not consistent. Brown and Barrett (2011) tested these mediation effects based on the data from the Americans' Changing Lives Study, and found that perceived support did not significantly predict depressive symptoms among older adults with vision impairment. On the contrary, Bookwala and Lawson (2011) conducted a study by using path analysis showing that older adults' functional limitations and social isolation played mediating roles on the relationship between self-rated vision impairment and depressive symptoms (Bookwala and Lawson, 2011). Similarly, in a separate study conducted in Amsterdam, the size of the social network among older adults played a mediating role in the association between vision impairment and depressive symptoms (van Nispen et al., 2016). These studies examined one domain of social support (Bookwala and Lawson, 2011; van Nispen et al., 2016) and ignored other ways to gauge social support. In fact, social support includes multiple domains. Lynch (1998) operationalised 
the role of social support in various ways, with at least three distinct dimensions: structure, function and perceived quality. Each aspect of social support was independently related to depressive symptoms (Chi and Chou, 2001). Additionally, the social support characteristics such as who provides the support and forms of support may influence the wellbeing of older adults (Merz and Huxhold, 2010). Individuals are likely to maintain various relationships to achieve a good sense of wellbeing (Weiss, 1974). Some of these provisions are typically provided by family, sibling, friends and neighbours (Lynch, 1998; Campbell et al., 1999; Brown et al., 2009; Li and Zhang, 2015). Therefore, it is important to examine multiple domains of social support (i.e. support from friends, support from family, etc.), the mediating roles of multiple domains of social support between vision impairment and depressive symptoms, and how this association varies by support type and provider in older adults.

China has the largest number of visually impaired residents in the world (World Health Organization, 2012). However, to the best of our knowledge, only one study has examined the potential mediators on the relationship between vision impairment and quality of life among the Chinese population (Wang et al., 2008b). The mediator examined was spirituality. Therefore, it is important to examine the potential mediators of functional limitations and social support on the relationship between vision impairment and depressive symptoms with evidence from China to expand our understanding of additional factors that could influence this relationship. A better understanding of these relationships will help health-care providers and policy makers to develop clinical and policy interventions to improve the health and wellbeing of older adults.

The purpose of this study was to examine how functional limitations and social support mediate the relationship between vision impairment and depressive symptoms. We hypothesised that vision impairment would be associated with greater depressive symptoms and that more functional limitations and less social support would partially account for this association. We predicted that these relationships would exist after controlling for the socio-demographic variables which are known to be related to vision impairment and depressive symptoms in older adults, such as age, gender, education level and marital status. We further assessed what types of functional limitations (i.e. activities of daily living (ADLs) and instrumental ADLs (IADLs)) and social support (i.e. support from friends, support from family, etc.) mediated the relationship between vision impairment and depressive symptoms.

\section{Methods}

\section{Sample and procedures}

We conducted this study from January 2014 to July 2014 among older adults aged 60 and above in Jing'an district, a central part of Shanghai, China. The sampling and recruitment methods are as follows. The Civil Affairs Bureau of Jing'an District had a list of all the residents in their community. We used this list as a sample frame and randomly selected study participants from the sample. Trained interviewers conducted a face-to-face interview with study participants using a structured questionnaire. From the population of 56,190 persons, 1,875 individuals 
were selected to enrol in the study, and a total of 1,233 participants completed the interviews. In the study, participants whose Mini-Mental State Examination (MMSE) score (Katzman et al., 1988) was lower than $20(\mathrm{~N}=87)$ were excluded, and participants with missing values of the Geriatric Depression Scale (GDS) $(\mathrm{N}=53)$ were deleted. The final sample included a total of 1,093 older adults.

\section{Measures}

Vision impairment

Self-rated vision status is defined by asking patients to rate the global quality of their vision from poor to good (El-Gasim et al., 2013). This method is widely used in scientific studies and routine assessments because it is simple and has been demonstrated to be a valid measure of vision impairment (Saaddine et al., 1999; Crews et al., 2014). For example, El-Gasim et al. (2013) studied the association between self-rated vision function and clinical vision tests, and found that better self-rated vision status was associated with better visual acuity, contrast sensitivity, stereoacuity and visual fields. In our study, we used self-rated vision status to measure vision impairment: 'Which statement best describes your present vision?' Response categories were as follows: $1=$ normal: no vision impairment or a little vision impairment but having no difficulty in managing familiar surroundings; 2 = moderate impairment: some vision impairment and having some difficulty in managing familiar surroundings; 3 = severe impairment: low vision or blindness (after wearing glasses or contact lenses) and needing help to take care of oneself even under familiar surroundings.

\section{Functional limitations}

The functional limitations scale included ADLs and IADLs (Lawton and Brody, 1969). ADL items included eating, walking, toileting, dressing, bathing, washing face and brushing teeth. IADL items included tasks such as doing housework, taking medicine, washing clothes, shopping, cooking, taking a bus, making phone calls and managing money. Responses were scored on a four-point scale $(1=$ no difficulty, $4=$ unable to). Higher total scores indicated more functional limitations. The Cronbach's alpha reliability coefficients of ADLs and IADLs in our study were 0.907 and 0.942 , respectively.

\section{Social support}

Social support was assessed using the Social Support Rating Scale by a Chinese researcher (Xiao, 1994) and the scale has been widely used in China due to its high reliability and validity (Wang et al., 2015; Nie et al., 2017). It consisted of 14 items. The Cronbach's alpha for this scale was 0.745 in this study. We evaluated the 14 items of social support by using an exploratory factor analysis. After deleting the items with a loading below 0.40 , results of this analysis are depicted in Table 1 . The most important factor explained 14.57 per cent of the variance, and it was related to friends support (FRS). The second, third, fourth and fifth factors explained an additional 12.41, 12.16, 12.09 and 10.63 per cent of the variance, respectively, and were related to relatives support (RES), calamity support (CAS), family support (FAS) and talking/asking for help (TAH). A total of 61.85 per 
Table 1. Factor loadings of items of social support using exploratory factor analysis

\begin{tabular}{|c|c|c|c|c|c|}
\hline Items $^{1}$ & FRS & FAS & RES & CAS & TAH \\
\hline How many close friends do you have? $(0=0 ; 1=1-2 ; 2=3-5 ; 3=6$ or more $)$ & 0.643 & & & & \\
\hline $\begin{array}{l}\text { How close is the relationship between you and your neighbours? }(0=\text { we never care about each other; } 1=\text { we rarely } \\
\text { care about each other; } 2=\text { some neighbours care about me very much; } 3=\text { most of my neighbours care about me } \\
\text { very much) }\end{array}$ & 0.649 & & & & \\
\hline $\begin{array}{l}\text { How close is the relationship between you and your colleagues? }(0=\text { we never care about each other; } 1=\text { we rarely care } \\
\text { about each other; } 2 \text { = some colleagues care about me very much; } 3=\text { most of my colleagues care about me very much) }\end{array}$ & 0.763 & & & & \\
\hline How often do you take part in group activities? ( $0=$ never; $1=$ sometimes; $2=$ often; $3=$ very often) & 0.689 & & & & \\
\hline How much support does your spouse give you? ( 0 = none; 1 = rare; 2 = fair; 3 = full support) & & 0.833 & & & \\
\hline How much support do your offspring give you? $(0=$ none; 1 = rare; 2 = fair; 3 = full support) & & 0.433 & & & \\
\hline $\begin{array}{l}\text { How close was your relationship with your family in terms of living arrangement during the past year? }(0=I \text { tried not } \\
\text { to live with my family members and lived alone; } 1=I \text { moved frequently and shared rooms with people whom I did } \\
\text { not know; } 2=\text { I lived with colleagues or friends; } 3=I \text { lived with family) }\end{array}$ & & 0.845 & & & \\
\hline How much support do your parents give you? $(0=$ none; 1 = rare; 2 = fair; 3 = full support $)$ & & & 0.670 & & \\
\hline How much support do your siblings give you? ( 0 =none; 1 = rare; 2 = fair; 3 = full support) & & & 0.746 & & \\
\hline How much support do the other members of your family give you? ( $0=$ none; $1=$ rare; $2=$ fair; $3=$ full support) & & & 0.802 & & \\
\hline $\begin{array}{l}\text { In the past, how many resources did you have that could give financial support to you when you encountered a } \\
\text { situation of distress?* }\end{array}$ & & & & 0.901 & \\
\hline $\begin{array}{l}\text { In the past, how many resources did you have that could give emotional support to you when you encountered a } \\
\text { situation of distress?* }\end{array}$ & & & & 0.852 & \\
\hline $\begin{array}{l}\text { How did you express distress? }(0=I \text { never talk to anyone; } 1=I \text { talked to my best friend; } 2=1 \text { talked when friends } \\
\text { asked; } 3=1 \text { talked very often to others to gain help) }\end{array}$ & & & & & 0.748 \\
\hline $\begin{array}{l}\text { How did you ask for help when you encountered distress? }(0=1 \text { relied on myself and never asked for help; } 1=1 \text { rarely } \\
\text { asked for help; } 2=I \text { sometimes asked for help; } 3=I \text { asked help from family, relatives and organisations very often) }\end{array}$ & & & & & 0.859 \\
\hline
\end{tabular}

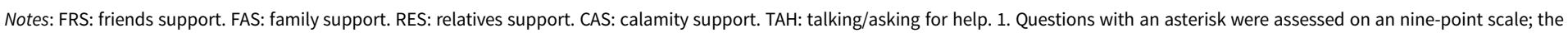
others were assessed on a four-point scale. 
cent of the variance of social support was explained by these five factors. The friends support included four items (close friends, neighbour relationship, colleague relationship and group activities); the relatives support included three items (parents support, siblings support and other family members support); the family support included three items (spouse support, offsprings support and family relationship); the calamity support included two items (financial support resources and emotional support resources) and the talking/asking for help included two items (sharing distress and asking for help). The score of each item ranged from 0 to 3 , except the items of financial support resources and emotional support resources which ranged from 0 to 8 .

We calculated the mean scores of factors grouped by vision impairment, as shown in Table 2. By analysis of variance, friends support, family support and relatives support showed significant difference among different vision impairment groups $(p<0.05)$. Calamity support and talking/asking for help were not significantly associated with vision impairment $(p>0.05)$, therefore they were deleted from the subsequent tests.

\section{Depressive symptoms}

Depressive symptoms were assessed using the GDS (D'Ath et al., 1994). Respondents were asked how in the past week they felt about each of the following: satisfaction with ones' life, abandonment of activities and interests, emptiness, boredom, spirits, anxiousness, happiness, helplessness, preference to stay at home, problems with memory, wonderfulness, energy, worthlessness, hopelessness, better off than other people. Responses were scored on a yes/no scale $(1=$ yes, $0=$ no). The 15 -item GDS is a valid screening tool for depressive symptoms in the Chinese population (Lai et al., 2010). The internal consistency reliability of the KuderRichardson Formula 20 (KR-20) of this scale was 0.830. Scores on the GDS range from 0 to 15 , with a higher score indicating worse depressive symptoms.

\section{Analytic techniques}

SPSS 17.0 for Windows (SPSS Inc., Chicago, IL) was used for preliminary analyses, including normality tests of the data, descriptive statistics of the variables and exploratory factor analysis for social support. Before modelling the latent constructs' interrelationship in a structural equation model (SEM), we performed the Confirmatory Factor Analysis (CFA) for the latent variables (Anderson and Gerbing, 1988). To investigate all the measurement issues and examine structural relationships among sets of variables simultaneously, SEM were used (Baumgartner and Homburg, 1996), using IBM-SPSS AMOS 20 software. To test the hypothesised mediation effects more effectively, the bootstrapping method was selected (Williams and MacKinnon, 2008; Hayes, 2009). We used the program PRODCLIN (Mackinnon et al., 2007) to test the specific indirect effect of confidence limits.

\section{Results}

\section{Participant characteristics}

Table 2 presents the characteristics of the participants. With regard to vision impairment, 67.7 per cent of the respondents were normal, 26.3 per cent reported 
Table 2. Characteristics of the study population

\begin{tabular}{|c|c|c|c|c|c|}
\hline Variables & Normal & $\begin{array}{l}\text { Moderate } \\
\text { impairment }\end{array}$ & $\begin{array}{c}\text { Severe } \\
\text { impairment }\end{array}$ & Total & $p$ \\
\hline N & 740 & 288 & 65 & 1,093 & \\
\hline \multicolumn{6}{|c|}{ Mean values (SD) or percentages } \\
\hline Age in years & $70.3(8.58)$ & $74.5(8.70)$ & $76.2(9.35)$ & $71.7(8.91)$ & $<0.001$ \\
\hline Gender male (\%) & 48 & 42 & 43 & 46 & 0.235 \\
\hline Education (years) & $11.4(3.50)$ & $10.9(4.22)$ & $10.3(4.24)$ & $11.2(3.76)$ & 0.02 \\
\hline Spouse status (\%) & 77.4 & 74.0 & 58.5 & 75.4 & 0.002 \\
\hline Income $(\%):^{1,2}$ & & & & & 0.068 \\
\hline 1 & 3.1 & 3.8 & 4.6 & 3.4 & \\
\hline 2 & 76.8 & 71.5 & 86.2 & 75.9 & \\
\hline 3 & 20.1 & 24.7 & 9.2 & 20.7 & \\
\hline ADLs & $6.3(1.74)$ & $6.5(1.69)$ & $7.9(3.62)$ & $6.5(1.92)$ & $<0.001$ \\
\hline IADLs & $8.9(3.58)$ & $9.2(3.47)$ & $13.0(6.65)$ & $9.3(3.91)$ & $<0.001$ \\
\hline Social support & $22.9(7.69)$ & $21.5(6.81)$ & $18.4(6.63)$ & $22.3(7.49)$ & $<0.001$ \\
\hline FRS & 6.9 (3.13) & 6.5 (2.99) & $4.8(2.69)$ & 6.7 (3.11) & $<0.001$ \\
\hline FAS & $7.4(2.41)$ & $7.1(2.54)$ & $6.4(2.78)$ & $7.3(2.48)$ & 0.005 \\
\hline RES & $2.5(2.62)$ & $1.9(2.21)$ & $1.6(2.23)$ & $2.3(2.51)$ & 0.001 \\
\hline CAS & $3.2(2.23)$ & $3.0(2.01)$ & $3.0(2.05)$ & $3.1(2.16)$ & 0.326 \\
\hline TAH & $3.0(1.82)$ & $3.0(1.78)$ & $2.7(1.82)$ & $2.9(1.81)$ & 0.390 \\
\hline GDS & $2.0(2.74)$ & $2.5(2.70)$ & $4.5(4.07)$ & $2.3(2.88)$ & $<0.001$ \\
\hline
\end{tabular}

Notes: SD: standard deviation. ADLs: activities of daily living. IADLS: instrumental activities of daily living. FRS: friends support. FAS: family support. RES: relatives support. CAS: calamity support. TAH: talking/asking for help. GDS: Geriatric Depression Scale. $1.1=<2,000$ CNY monthly (equivalent to US $\$ 300$ in 2014); $2=2,000-3,999$ CNY (US $\$ 450$ ); $3=>4,000$ CNY. 2. Values for $p$ based on chi-square test.

moderate vision impairment and 5.9 per cent reported severe vision impairment. Participants with greater vision impairment were older, and had a lower education level, poorer ADLs and IADLs, less social support and fewer of them had a spouse. The mean GDS score of the group of normal vision, moderate vision impairment and severe vision impairment was 2.04, 2.54 and 4.46, respectively. The greater the severity of vision impairment, the more depressive symptoms were reported.

\section{Confirmatory Factor Analysis}

This full CFA model consists of the latent variables of ADLs, IADLs, friends support, family support, relatives support and depressive symptoms. To minimise the effects of nuisance factors at a lower level of generality and improve the model fit, all six items of ADLs and eight items of IADLs were parcelled due to being unidimensional and having high alpha coefficients (Little et al., 2002). Because items on the GDS were binary variables (yes/no), the variable depressive symptoms 
were parcelled out as well (Bandalos and Finney, 2001). The Maximum Likelihood (ML) approach was used to estimate the parameters and assess the model (Gao et al., 2008), and the Bollen-Stine bootstrap procedure (2,000 replicates) was used to estimate chi-square and correct the model fit indices (Bollen and Stine, 1992). The Bollen-Stine bootstrap was $p=0.000$, therefore the model was considered correct.

There were good fit indices for the measurement model: Root Mean Square Error of Approximation (RMSEA) $=0.006$, Comparative Fit Index $(\mathrm{CFI})=1.00$, Relative Fit Index $(\mathrm{RFI})=0.97$, Tucker-Lewis Index $(\mathrm{TLI})=1.00$, Normed Fit Index $(\mathrm{NFI})=0.98, \chi^{2} / \mathrm{df}($ degrees of freedom $)=1.05$. Most of the factor loadings were over or close to 0.4 , and all loadings were statistically significant $(p<$ 0.001). All Composite Reliability values were over 0.6 , which we considered desirable (Bagozzi and Yi, 1988). All the correlations between exogenous constructs were below 0.7 , indicating a good discriminant validity (Grewal et al., 2004).

\section{Structural Equation Model testing}

The initial SEM consisted of primary variables (the six latent variables) and the independent variable of vision impairment, covariates (demographic variables) and pathways in the initial theoretical model, plus empirically determined pathways from covariates to the latent variables. The Maximum Likelihood (ML) approach and the Bollen-Stine bootstrap procedure were used here as well. There were good fit indices for Model 1 : RMSEA $=0.010, \mathrm{NFI}=0.98, \mathrm{CFI}=1.00, \mathrm{TLI}=1.00$, Incremental Fit Index $(\mathrm{IFI})=1.00, \mathrm{RFI}=0.97, \chi^{2} / \mathrm{df}=1.05$. The $R^{2}$ of ADLs, IADLs, friends support, family support, relatives support and depressive symptoms was $0.104,0.179,0.155,0.852,0.089$ and 0.234 , respectively. The primary variables and coefficients of paths in Model 1 are shown in Figure 1.

From Model 1, we drew the following conclusions: (a) respondents reporting more vision impairment also reported a higher level of functional limitations (poorer ADLs and IADLs) and a lower level of friends support; (b) less friends support, family support, relatives support and poorer IADLs were related to more depressive symptoms; (c) the associations between vision impairment and family support, vision impairment and relatives support were not statistically significant ( $p>0.05)$; (d) the association between ADLs and depressive symptoms was not statistically significant $(p>0.05)$.

\section{Testing mediation hypotheses}

As shown in Table 3, the total effect, the direct effect and the total indirect effect from vision impairment to depressive symptoms were statistically significant in Model 1. The ratio of the total indirect effect to the total effect was 37.35 per cent. By Mackinnon PRODCLIN test, we concluded that the 95 per cent confidence intervals for the indirect effects through friends support and IADLs did not contain zero, which indicated that these two factors were playing mediating roles on the relationship between vision impairment and depressive symptoms. The friends support contributed mainly to the total indirect effect, and the ratio of the specific indirect effect to the total indirect effect was 52.69 per cent. But the 95 per cent 


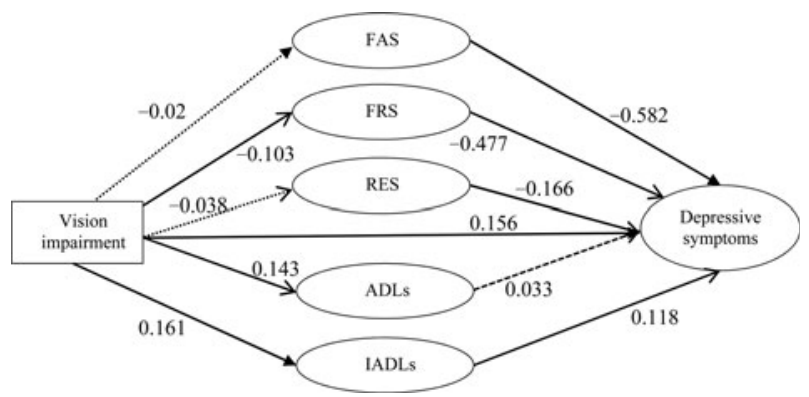

Figure 1. Structural model for vision impairment and depressive symptoms in Model 1. The dashed lines indicate that the relationship between the two variables was NOT statistically significant $(p>0.05)$. The other solid lines indicate that the relationship between the two variables was statistically significant $(p \leq 0.05)$. Notes: FAS: family support. FRS: friends support. RES: relatives support. ADLs: activities of daily living. IADLS: instrumental activities of daily living.

Table 3. Mediation effects testing in Model 1

\begin{tabular}{|c|c|c|c|c|c|c|c|}
\hline \multirow[b]{3}{*}{ Effects } & \multirow{3}{*}{$\begin{array}{l}\text { Point } \\
\text { estimate }\end{array}$} & \multicolumn{4}{|c|}{ Bootstrapping } & \multirow{2}{*}{\multicolumn{2}{|c|}{$\begin{array}{c}\text { Mackinnon } \\
\text { PRODCLIN 95\% Cl }\end{array}$}} \\
\hline & & \multicolumn{2}{|c|}{$\begin{array}{c}\text { Bias-corrected } \\
95 \% \mathrm{Cl}\end{array}$} & \multicolumn{2}{|c|}{ Percentile $95 \% \mathrm{Cl}$} & & \\
\hline & & Lower & Upper & Lower & Upper & Lower & Upper \\
\hline Total & 0.249 & 0.141 & 0.360 & 0.141 & 0.359 & & \\
\hline Direct & 0.156 & 0.061 & 0.260 & 0.051 & 0.251 & & \\
\hline Indirect & 0.093 & 0.045 & 0.154 & 0.046 & 0.155 & & \\
\hline \multicolumn{8}{|c|}{ Specific indirect effect: } \\
\hline FRS & 0.049 & & & & & 0.015 & 0.089 \\
\hline FAS & 0.013 & & & & & -0.005 & 0.040 \\
\hline RES & 0.006 & & & & & -0.001 & 0.020 \\
\hline ADLs & 0.005 & & & & & -0.002 & 0.015 \\
\hline IADLs & 0.019 & & & & & 0.006 & 0.037 \\
\hline
\end{tabular}

Notes: FRS: friends support. FAS: family support. RES: relatives support. ADLs: activities of daily living. IADLs: instrumental activities of daily living. Cl: confidence interval.

confidence intervals for the indirect effects through family support, relatives support and ADLs contained zero, which indicated that these three factors did not play mediating roles on the relationship between vision impairment and depressive symptoms.

These results suggest that (a) vision impairment was directly associated with depressive symptoms; (b) the association between vision impairment and depressive symptoms was partially mediated by friends support and IADLs; and (c) friends support played a more important mediating role than IADLs on the relationship between vision impairment and depressive symptoms. 


\section{Discussion}

The findings indicate a strong relationship between vision impairment and depressive symptoms after controlling for socio-demographic variables. A few studies explored the mediating mechanisms through which vision impairment is associated with depressive symptoms (Bookwala and Lawson, 2011; Brown and Barrett, 2011; van Nispen et al., 2016). This is the first study conducted in China and the findings from this study provided important evidence for the adverse effect of vision impairment on depressive symptoms. Additionally, it provided a clear explanatory mechanism for this relationship. In particular, for the first time we differentiated types of social support and tested the potential mediating roles of friends support, family support and relatives support on the relationship between vision impairment and depressive symptoms. Furthermore, we assessed the potential separate mediating roles of ADLs and IADLs on the relationship between vision impairment and depressive symptoms.

The results of this study supported all of our hypotheses. Consistent with a previous study (Wang et al., 2008a), vision impairment was directly associated with a lower level of friends support. Vision impairment was associated with fewer close friends, fewer close neighbour relationships and colleague relationships, and a lower frequency of participation in group activities. These findings echoed the exchange theory (Gouldner, 1960), positing that vision impairment makes it difficult for older adults to reciprocate. Breaking the balance of support received and provided can lead to the end of a relationship (Aartsen et al., 2004). The result that lower levels of family support, relatives support and friends support were associated with greater depressive symptoms confirmed previous findings that more positive social support is related to fewer depressive symptoms (Mcllvane and Reinhardt, 2001; Papadopoulos et al., 2014). While some research indicated that a higher level of support received was associated with greater depressive symptoms among visually impaired older adults mainly because of greater disability and psychological consequences of depending on others for basic daily needs (Cimarolli and Boerner, 2005), abundant studies have demonstrated that affective support has the most important positive impact on mental health (Lee et al., 1996; Reinhardt et al., 2006). Friends (including neighbours and colleagues) are important affective support providers. In our study, we found that decrease of friends support among the visually impaired older adults would result in greater depressive symptoms.

Our findings supported previous findings that vision impairment was associated with IADL disability (Hochberg et al., 2012), and functional limitations and social support played mediating roles on the association between vision impairment and depressive symptoms (Bookwala and Lawson, 2011). However, these findings were not aligned with a previous study that showed adults with low visual ability received higher social support than the general population (Kempen et al., 2014). It is possible that Kempen's study recruited participants seeking vision rehabilitation services in the Netherlands. The different recruitment strategy and study sample may yield different results.

One advantage of conducting mediation analysis was to identify potential pathways to gain a better understanding of the potential association between vision impairment and depressive symptoms. This analysis also allowed us to obtain an accurate measure of the association. Based on the aforementioned findings, our 
study offers important new insights to improve our current understanding of the link between depressive symptoms and vision impairment. The mediating mechanism has implications for interventions aimed at decreasing the depressive symptoms of older adults with vision impairment.

Our findings reinforce the findings that (a) depressive symptoms may be reduced by increasing one's social support, and (b) a higher level and better quality of friendship is associated with better adaptation to vision impairment (Reinhardt, 1996; McIlvane and Reinhardt, 2001). Due to stigma in Chinese society, older adults with vision impairment are often labelled as a vulnerable population, and their social interactions are limited for safety reasons. We should recognise the vulnerability of the elderly with vision impairment, however, we should not limit the elderly population's social interaction and social participation. The Chinese government should focus on improving the policies related to community support and family support to enhance social support and care services for older adults with vision impairment. Friends, neighbours, colleagues and volunteers may provide support to older adults with vision impairment by having frequent home visits or regular phone calls. It is also essential to help and encourage older adults with vision impairment to take part in group recreational activities. We found that vision impairment of older adults was not statistically associated with calamity support and talking/asking for help, implying that when these older adults encounter difficulties, they could potentially attain a similar amount of help as those with normal vision. Therefore, more social support should be given to vision-impaired older adults in daily routines.

Maintaining social contact contributed to an improved quality of life for people with vision impairment (Heine and Browning, 2004; Bowes et al., 2018) and environmental variables may play a role in the social participation of older adults with vision impairment (Cimarolli et al., 2017). Clinicians and other health-care providers should evaluate the impact of visual ability on their patients' functional limitations, and make transportation services more accessible to these individuals (Bookwala and Lawson, 2011). In China, accessible transportation services and facilities for the disabled are very poor, which further restricts the activities of older adults with vision impairment. Therefore, it is necessary to increase infrastructure investment for the disabled elderly.

There are several limitations in this study worthy of mention. First, the sample consisted of older adults from a developed urban district in China. It may not be representative of older adults living in developing urban districts or in rural areas. However, it may represent China's future development trend. At the same time, it was difficult for us to assess the correctness of the self-reported social support and GDS of the elderly participants with low cognitive abilities, and we had to exclude the participants whose MMSE score was lower than 20 in this study. Determining how to objectively assess the social support and GDS of these older adults needs further research. Second, vision impairment was self-reported, not measured by an objective measurement; and our study did not investigate the cause of vision impairment. Future research measuring vision impairment by a valid and reliable measurement is needed. Lastly, our study was cross-sectional and there may be additional interaction effects among functional limitations, social support and depressive symptoms. We were not able to tease out the time sequence 
of the variables between vision impairment and depressive symptoms. In the future, using longitudinal data to examine the relationship of these variables is needed. However, this study greatly contributes to the knowledge of mediating mechanisms between vision impairment and depressive symptoms. It found that vision impairment was directly associated with a higher level of depressive symptoms, and the association was partially mediated by functional limitations (IADLs) and social support (friends support). These findings can provide clinical and policy implications to improve the life of older adults with vision impairment.

Acknowledgement. We thank Darina Petrovsky for her editorial assistance.

\section{References}

Aartsen MJ, Tilburg T, Smits CHM and Knipscheer KCPM (2004) A longitudinal study of the impact of physical and cognitive decline on the personal network in old age. Journal of Social and Personal Relationships 21, 249-266.

Anderson JC and Gerbing DW (1988) Structural equation modeling in practice: a review and recommended two-step approach. Psychological Bulletin 103, 411-423.

Augustin A, Sahel JA, Bandello F, Dardennes R, Maurel F, Negrini C, Hieke K and Berdeaux G (2007) Anxiety and depression prevalence rates in age-related macular degeneration. Investigative Ophthalmology and Visual Science 48, 1498-1503.

Bagozzi RP and Yi Y (1988) On the evaluation of structural equation models. Journal of the Academy of Marketing Science 16, 74-94.

Bandalos DL and Finney SJ (2001) Item parceling issues in structural equation modeling. In Marcoulides GA and Schumacker RE (eds), New Developments and Techniques in Structural Equation Modeling. Mahwah, NJ: Lawrence Erlbaum Associates, pp. 269-296.

Baumgartner $\mathbf{H}$ and Homburg C (1996) Applications of structural equation modeling in marketing and consumer research: a review. International Journal of Research in Marketing 13, 139-161.

Beekman ATF, Kriegsman DMW, Deeg DJH and Tilburg WV (1995) The association of physical health and depressive symptoms in the older population: age and sex differences. Social Psychiatry and Psychiatric Epidemiology 30, 32-38.

Bernabei V, Morini V, Moretti F, Marchiori A, Ferrari B, Dalmonte E, Ronchi DD and Atti AR (2011) Vision and hearing impairments are associated with depressive-anxiety syndrome in Italian elderly. Aging and Mental Health 15, 467-474.

Blomgren J, Breeze E, Koskinen S and Martikainen P (2012) Help from spouse and from children among older people with functional limitations: comparison of England and Finland. Ageing \& Society 32, 905-933.

Bollen KA and Stine RA (1992) Bootstrapping goodness-of-fit measures in structural equation models. Sociological Methods and Research 21, 205-229.

Bookwala J and Lawson B (2011) Poor vision, functioning, and depressive symptoms: a test of the activity restriction model. The Gerontologist 51, 798-808.

Bowes A, Dawson A, Greasley-Adams C and McCabe L (2018) Developing best practice guidelines for designing living environments for people with dementia and sight loss. Ageing \& Society 38, 900-925.

Branch LG, Horowitz A and Carr C (1989) The implications for everyday life of incident self-reported visual decline among people over age 65 living in the community. Gerontologist 29, 359-365.

Brody BL, Gamst AC, Williams RA, Smith AR, Lau PW, Dolnak D, Rapaport MH, Kaplan RM and Brown SI (2001) Depression, visual acuity, comorbidity, and disability associated with age-related macular degeneration. Ophthalmology 108, 1893-1900.

Brown RL and Barrett AE (2011) Visual impairment and quality of life among older adults: an examination of explanations for the relationship. Journals of Gerontology: Social Sciences 66, 364-373.

Brown SC, Mason CA, Spokane AR, Cruza-Guet MC, Lopez B and Szapocznik J (2009) The relationship of neighborhood climate to perceived social support and depressive symptoms in older Hispanic immigrants in Miami, Florida. Journal of Aging and Health 21, 431-459. 
Burmedi D, Becker S, Heyl V, Wahl H-W and Himmelsbach I (2002) Behavioral consequences of age-related low vision: a narrative review. Visual Impairment Research 4, 15-45.

Campbell LD, Connidis IA and Davies L (1999) Sibling ties in later life: a social network analysis. Journal of Family Issues 20, 114-148.

Chi I and Chou K-L (2001) Social support and depression among elderly Chinese people in Hong Kong. Aging and Human Development 52, 231-252.

Cimarolli VR, Boerner K, Reinhardt JP, Horowitz A, Wahl HW, Schilling O and Brennan-Ing M (2017) A population study of correlates of social participation in older adults with age-related vision loss. Clinical Rehabilitation 31, 115-125.

Cimarolli VR and Boerner K (2005) Social support and well-being in adults who are visually impaired. Journal of Visual Impairment and Blindness 99, 521-534.

Crews JE, Chou CF, Zhang X, Zack MM and Saaddine JB (2014) Health-related quality of life among people aged $\geqslant 65$ years with self-reported visual impairment: findings from the 2006-2010 behavioral risk factor surveillance system. Ophthalmic Epidemiology 21, 287-296.

D'Ath P, Katona P, Mullan E, Evans S and Katona C (1994) Screening, detection and management of depression in elderly primary care attenders. I: The acceptability and performance of the 15 item Geriatric Depression Scale (GDS15) and the development of short versions. Family Practice 11, 267-270.

El-Gasim M, Munoz B, West SK and Scott AW (2013) Associations between self-rated vision score, vision tests, and self-reported visual function in the Salisbury Eye Evaluation Study. Investigative Ophthalmology and Visual Science 54, 6439-6445.

Evans JR, Fletcher AE and Wormald RPL (2007) Depression and anxiety in visually impaired older people. Ophthalmology 114, 283-288.

Gao S, Mokhtarian PL and Johnston RA (2008) Nonnormality of data in structural equation models. Transportation Research Record: Journal of the Transportation Research Board 2082, 116-124.

Gouldner AW (1960) The norm of reciprocity: a preliminary statement. American Sociological Review 25, 161-178.

Grewal R, Cote JA and Baumgartner H (2004) Multicollinearity and measurement error in structural equation models: implications for theory testing. Marketing Science 23, 519-529.

Guerette AR and Smedema SM (2011) The relationship of perceived social support with well-being in adults with visual impairments. Journal of Visual Impairment and Blindness 105, 425-439.

Hayes AF (2009) Beyond Baron and Kenny: statistical mediation analysis in the New Millennium. Communication Monographs 76, 408-420.

Hayman KJ, Kerse NM, La Grow SJ, Wouldes T, Robertson MC and Campbell AJ (2007) Depression in older people: visual impairment and subjective ratings of health. Optometry and Vision Science 84, 1024-1030.

Heine H and Browning C (2004) The communication and psychosocial perceptions of older adults with sensory loss: a qualitative study. Ageing \& Society 24, 113-130.

Hochberg C, Maul E, Chan ES, Van LS, Ferrucci L, Friedman DS and Ramulu PY (2012) Association of vision loss in glaucoma and age-related macular degeneration with IADLs disability. Investigative Ophthalmology and Visual Science 53, 3201-3206.

Horowitz A, Reinhardt JP, Boerner K and Travis LA (2003) The influence of health, social support quality and rehabilitation on depression among disabled elders. Aging and Mental Health 7, 342-350.

Hybels CF, Blazer DG and Pieper CF (2001) Toward a threshold for subthreshold depression: an analysis of correlates of depression by severity of symptoms, using data from an elderly community sample. The Gerontologist 41, 357-365.

Jang Y, Mortimer JA, Haley WE, Small BJ, Chisolm TEH and Graves AB (2003) The role of vision and hearing in physical, social, and emotional functioning among older adults. Research on Aging 25, 172-191.

Jin Y-P and Wong DT (2008) Self-reported visual impairment in elderly Canadians and its impact on healthy living. Canadian Journal of Ophthalmology 43, 407-413.

Katzman R, Zhang MY, Ouang Y-Q, Wang ZY, Liu WT, Yu E, Wong SC, Salmon DP and Grant I (1988) A Chinese version of the Mini-Mental State Examination; impact of illiteracy in a Shanghai dementia survey. Journal of Clinical Epidemiology 41, 971-978.

Keller BK, Ba JLM, Thomas VS and Potter JF (1999) The effect of visual and hearing impairments on functional status. Journal of the American Geriatrics Society 47, 1319-1325. 
Kempen GIJM, Ranchor AV, Ambergen T and Zijlstra GAR (2014) The mediating role of disability and social support in the association between low vision and depressive symptoms in older adults. Quality of Life Research 23, 1039-1043.

Kim Y, Kwak Y and Kim JS (2015) The association between suicide ideation and sensory impairment among elderly Koreans. Aging and Mental Health 19, 658-665.

Lai D, Tong H, Zeng Q and Xu W (2010) The factor structure of a Chinese Geriatric Depression Scale-SF: use with alone elderly Chinese in Shanghai, China. International Journal of Geriatric Psychiatry 25, 503-510.

Lawton MP and Brody EM (1969) Assessment of older people: self-maintaining and instrumental activities of daily living. The Gerontologist 9, 179-186.

Lebowitz BD, Pearson JL, Schneider LS, Reynolds CF, Alexopoulos GS, Bruce ML, Conwell Y, Katz IR, Meyers BS, Morrison MF, Mossey J, Niederehe G and Parmelee P (1997) Diagnosis and treatment of depression in late life. JAMA: The Journal of the American Medical Association 278, 1186-1190.

Lee MS, Crittenden KS and Yu E (1996) Social support and depression among elderly Korean immigrants in the United States. International Journal of Aging and Human Development 42, 313-327.

Li T and Zhang Y (2015) Social network types and the health of older adults: exploring reciprocal associations. Social Science and Medicine 130, 59-68.

Little TD, William AC and Shahar G (2002) To parcel or not to parcel: exploring the question, weighing the merits. Structural Equation Modeling 9, 151-173.

Lynch SA (1998) Who supports whom? How age and gender affect the perceived quality of support from family and friends. The Gerontologist 38, 231-238.

Mackinnon DP, Fritz MS, Williams J and Lockwood CM (2007) Distribution of the product confidence limits for the indirect effect: Program PRODCLIN. Behavior Research Methods 39, 384-389.

McIlvane JM and Reinhardt JP (2001) Interactive effect of support from family and friends in visually impaired elders. Journals of Gerontology: Psychological Sciences 56, 374-382.

Merz EM and Huxhold O (2010) Wellbeing depends on social relationship characteristics: comparing different types and providers of support to older adults. Ageing \& Society 30, 843-847.

Nie C, Dai Q, Zhao R, Dong Y, Chen Y and Ren H (2017) The impact of resilience on psychological outcomes in women with threatened premature labor and spouses: a cross-sectional study in Southwest China. Health and Quality of Life Outcomes 15, 26, 1-10.

Papadopoulos K, Papakonstantinou D, Montgomery A and Solomou A (2014) Social support and depression of adults with visual impairment. Research in Developmental Disabilities 35, 1734-1741.

Penninx BW, Guralnik JM, Ferrucci L, Simonsick EM, Deeg DJ and Wallace RB (1998) Depressive symptoms and physical decline in community-dwelling older persons. JAMA: The Journal of the American Medical Association 279, 1720-1726.

Rees G, Xie J, Holloway EE, Sturrock BA, Fenwick EK, Keeffe JE and Lamoureux E (2013) Identifying distinct risk factors for vision-specific distress and depressive symptoms in people with vision impairment. Investigative Ophthalmology and Visual Science 54, 7431-7438.

Reinhardt JP (1996) The importance of friendship and family support in adaptation to chronic vision impairment. Journals of Gerontology: Psychological Sciences 51, 268-278.

Reinhardt JP, Boerner K and Horowitz A (2006) Good to have but not to use: differential impact of perceived and received support on well-being. Journal of Social and Personal Relationships 23, 117-129.

Reinhardt JP, Boerner K and Horowitz A (2009) Personal and social resources and adaptation to chronic vision impairment over time. Aging and Mental Health 13, 367-375.

Rovner BW and Casten RJ (2002) Activity loss and depression in age-related macular degeneration. American Journal of Geriatric Psychiatry 10, 305-310.

Rovner BW, Zisselman PM and Shmuely-Dulitzki Y (1996) Depression and disability in older people with impaired vision: a follow-up study. Journal of the American Geriatrics Society 44, 181-184.

Saaddine JB, Narayan KM, Engelgau MM, Aubert RE, Klein R and Beckles GL (1999) Prevalence of selfrated visual impairment among adults with diabetes. American Journal of Public Health 89, 1200-1205.

Schilling OK, Wahl HW, Horowitz A, Reinhardt JP and Boerner K (2011) The adaptation dynamics of chronic functional impairment: what we can learn from older adults with vision loss. Psychology and Aging 26, 203-213.

van Nispen RM, Vreeken HL, Comijs HC, Deeg DJ and van Rens GH (2016) Role of vision loss, functional limitations and the supporting network in depression in a general population. Acta Ophthalmologica 94, $76-82$. 
Wang CW, Chan CLW, Ho AHY and Xiong Z (2008a) Social networks and health-related quality of life among Chinese older adults with vision impairment. Journal of Aging and Health 20, 804-823.

Wang CW, Chan CLW, Ng S-M and Ho AHY (2008b) The impact of spirituality on health-related quality of life among Chinese older adults with vision impairment. Aging and Mental Health 12, 267-275.

Wang YH, Haslam M, Yu M, Ding J, Lu Q and Pan F (2015) Family functioning, marital quality and social support in Chinese patients with epilepsy. Health and Quality of Life Outcomes 13, 1-10.

Weiss R (1974) The provisions of social relationships. In Rubin Z (ed.), Doing Unto Others. Englewood Cliffs, NJ: Prentice-Hall, pp. 17-26.

West CG, Gildengorin G, Haegerstrom-Portnoy G, Schneck ME, Lott L and Brabyn JA (2002) Is vision function related to physical functional ability in older adults? Journal of the American Geriatrics Society 50, 136-145.

Williams J and MacKinnon DP (2008) Resampling and distribution of the product methods for testing indirect effects in complex models. Structural Equation Modeling 15, 23-51.

World Health Organization (2012) Global Data on Vision Impairment 2010. Available at http://www.who. int/blindness/GLOBALDATAFINALforweb.pdf.

Xiao SY (1994) Theoretic basis and application in research of social support rating scale. Journal of Clinical Psychiatry (China) 4, 98-100.

Cite this article: Gong X, Ni Z, Wu B (2020). The mediating roles of functional limitations and social support on the relationship between vision impairment and depressive symptoms in older adults. Ageing e Society 40, 465-479. https://doi.org/10.1017/S0144686X18001010 